JOURNAL OF APPIIED MECIANICAL
ENGINEERING AND RENEWABLE
ISAS Vol. $x$ No. $x(20 x \mathrm{x}) \mathrm{x}-\mathrm{xx} \quad$ ISSN Media Elektronik: $x \mathrm{x} x \mathrm{x}-\mathrm{x} x \mathrm{x} x$

\title{
Uji Kekerasan Bahan Gear Sprocket Dengan Campuran Timah
}

\author{
Normansyah ${ }^{1}$ Muh Anhar ${ }^{2}$ \\ ${ }^{12}$ Perawatan dan Perbaikian Mesin, Politeknik Negeri Ketapang \\ 1emai1: norman21.ismail@gmai
}

\begin{abstract}
The Material Test Process of Gear Sprocket includes the process of cutting the material used as the Material Test sample which is mixed or not mixed. In the sample that is mixed, namely the base metal that has been cut with a value ratio of 10: 2 Ounce of Material Gear Sprocket 10 and Tin Material 2 Ounces, fusion will be carried out for the process of blending / unifying the two types of material as sample material. Test the material with the mixing., while the Gear Sprocket material sample that was not mixed was also taken a load value of 10 Ounces, for the test sample where the mixing was not carried out. The test results data from the Gear Sprocket material sample with Tin mixing with four tests from several different surface parts obtained the value 51.5, 55, 50, $53 \mathrm{kgf}$. While the sample of the Gear Sprocket material without mixing the tin, the results obtained are the values of 50,51, 50, $50 \mathrm{kgf}$. In combining the Tin Material with the base metal Gear Sprocket with the ratio of 2 Ounce Tin Material and 10 Ounce Gear Sprocket Material, the hardness results are unstable, so the value obtained from the material being treated is obtained a value that is less likely, while the material test value of the Material Gear Sprockets that are not combined have good results from each surface even though the hardness value is slightly smaller than the result of the material being treated.
\end{abstract}

Keywords: Hardness Test, Gear Sprocket, Tin.

\begin{abstract}
Abstrak
Proses Uji bahan material Gear Sprocket meliputi proses pemotongan material yang digunakan sebagai sampel Uji Bahan yang dilakukan pencampuran maupun tidak dilakukan pencampuran. Dalam sampel yang dilakukan pencampuran yaitu Logam dasar yang sudah dilakukan pemotongan dengan perbandingan nilai 10:2 Ons Material Gear Sprocket 10 dan Material Timah 2 Ons, akan dilakukan peleburan untuk proses pemaduan/mempersatukan kedua jenis material tersebut sebagai bahan material sampel Uji bahan dengan pencampuran tersebut, sedangkan sampel material Gear Sprocket yang tidak dilakukan pencampuran juga diambil nilai beban 10 Ons, untuk sebagai sampel pengujian yang tidak dilakukan pencampuran tersebut.Data hasil pengujian dari Sampel material Gear Sprocket dengan pencampuran Timah dengan empat kali pengujian dari beberapa bagian permukaan yang berbeda didapat nilai 51,5, 55, 50, 53 kgf. Sedangkan Sampel material Gear Sprocket yang tanpa pencampuran Timah didapat hasil nilai 50, 51, 50, $50 \mathrm{kgf}$. didalam pemaduan Material Timah dengan logam dasar Gear Sprocket dengan perbandingan Material Timah 2 Ons dan Material Gear Sprocket 10 Ons didapat hasil kekerasan yang tidak stabil, sehingga nilai yang didapat dari material yang dilakukan perlakuan tersebut didapat nilai yang kurang memungkinkan, sedangkan nilai uji bahan dari Material Gear Sprocket yang tidak dilakukan pemaduan didapat hasil yang baik dari tiap-tiap permukaanya walaupun nilai kekerasannya sedikit lebih kecil dari hasil material yang dilakukan perlakuan.
\end{abstract}

Kata kunci: Uji Kekerasan,Gear Sprocket, Timah..

Diterima Redaksi: xx-xx-20xx | Selesai Revisi: xx-xx-20xx | Diterbitkan Online: xx-xx-20xx

\section{Pendahuluan}

Perkembangan dunia otomotif yang semakin pesat menuntut industri otomotif untuk selalu mengedepankan kemajuan teknologinya masing-masing, terutama dibidang kendaraan roda dua[1] Pemakaian baja paduan khusus pada dunia otomotif terus meningkat, seiring meningkatnya kendaraan bermotor di Indonesia, banyak komponen otomotif yang memakai baja paduan, diantaranya adalah Gear Sprocket belakang pada sepeda motor dan sebagainya.Peleburan merupakan sebuah proses pencairan/pengecoran suatu logam yang sudah dipadukan dengan logam-logam tertentu untuk 
dilakukannya pencetakan (Cavity) sesuai bentuk dan desain produk yang diinginkan[5]. Setelah logam cair tercetak dan tersolidasi selanjutnya produk atau cetakan logam tersebut akan disortir dan dilakukan pengujian, seperti pemanasan, penarikan, penekanan, penggoresan dan seterusnya, sesuai dengan kebutuhan pengujian struktur produk dan logam itu sendiri.[2] Dalam uji bahan ini proses peleburan digunakan untuk memadukan material Gear Sprocket dengan Timah sebagai sampel Uji bahan.

Setelah dilakukan peleburan pada Material dasar Gear Sprocket untuk pemaduan Timah, akan dilakukan penguji kekerasan dengan Hardnesst test jenis Rockwell begitu juga dengan Sampel dasar Gear Sprocket yang tidak dilakukan pemaduan Timah. melakukan penguji kekerasan dengan Rockwell ini yaitu bertujuan untuk mengetahui hasil nilai kekerasan Gear Sprocket dengan pemaduan Timah maupun tanpa pemaduan Timah.[6] Dalam penelitian bertujuan untuk mengetahui pengaruh timah terhadap nilai kekerasan material Gear Sprocket setelah dilebur/dipadukan dengan timah, dan seperti apa perbedaan nilai dengan material Gear Sprocket yang dipadukan dengan Timah

\section{Metode Penelitian}

Penelitian ini dilaukan di laboratorium Politeknik Negeri Ketapang,dengan menggunakan metode dalam pemngumpulan data yakni dengan metode:

a) Data primer, yang meliputi kegiatan praktek dan penelitian langsung kelapangan,yang meliputi proses perpaduan Gear dengan Timah, pengujian kekerasan dari masing-masing material Gear Sprocket yang sudah dilakukan perlakuan maupun tidak.[2]

b) Data sekunder, yang merupakan data yang didapat dari referensi penelitian yang sudah ada dari bahan bacaan internet yang dapat dipertanggung jawabkan kebenarannya untuk mendukung dan menguatkan konsep yang digunakan dalam penulisan penelitian ini

\section{Bahan dan Alat}

Dalam penelitian ini bahan alat yang digunakan mesin Rockwel,timah dan gear sprocket 415

\section{Diagram Alir}

Dalam proses pengujian dilaksankan dengan menggunakan diagram alir.

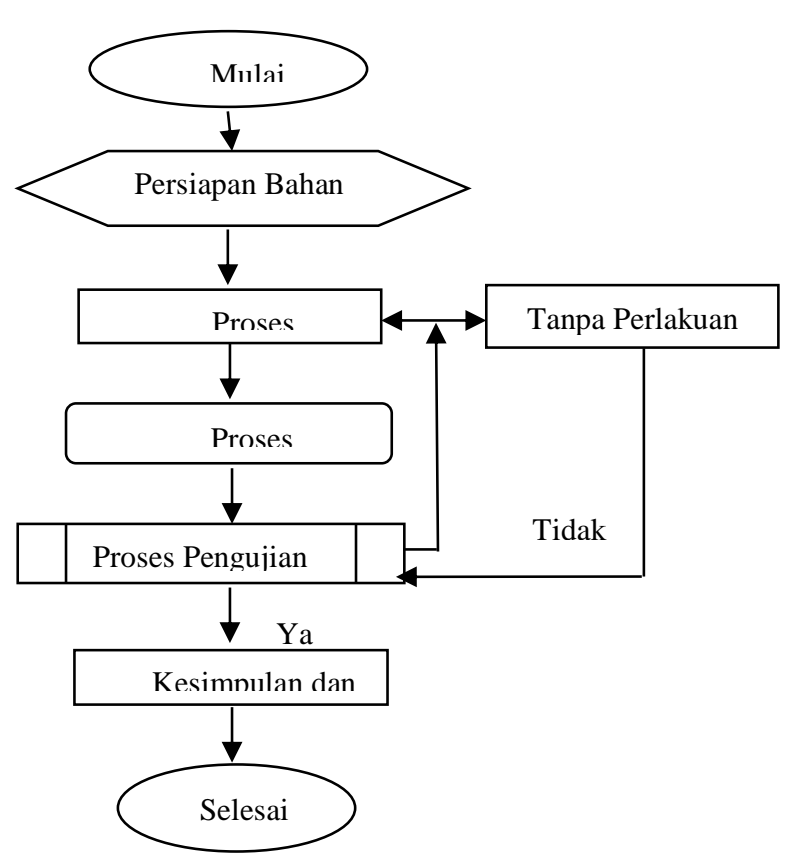

Gambar 1 Diagram Alir Proses Kerja Penelitian

\section{Hasil dan Pembahasan}

\subsection{Pemotongan Material Gear Sprocket dan Timah}

Pemotongan material gear seprocket yaitu untuk mengambil beberapa titik bagian, sebagai material untuk dijadikan sampel bahan uji yang dilakukan perlakuan maupun tanpa perlakuan, juga sama halnya dengan material timah itu sendiri, material yang akan digunakan sebagai bahan perlakuan material Gear Sprocket tersebut akan disatukan dengan cara dilebur sampai menyatu satu sama lainnya.[7]
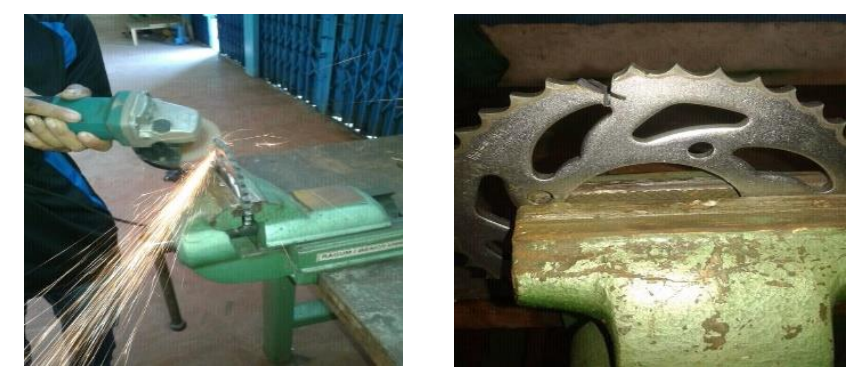

Gambar 2 Proses Pemotongan Material Gear Sprocket

\subsection{Penimbangan Material Untuk Sampel Perbandingan}

Setelah dilakukan pemotongan pada Material Gear Sprocket yang digunakan untuk sampel uji bahan, akan dilakukan penimbangan sebagai perbandingan sesuai masa jenis material itu sendiri, disini material Gear Sprocket yang akan dilakukan perlakuan sebesar 10 ons dan yang tanpa perlakun juga 10 ons.Tetapi dari salah satu jenis material tersebut akan dilebur dengan material

Journal of Applied Mechanical Engineering and Renewable Energy (JAMERE) 
Timah, yang diambil perbandingan dengan masa jenis Timah sebesar 2 ons.
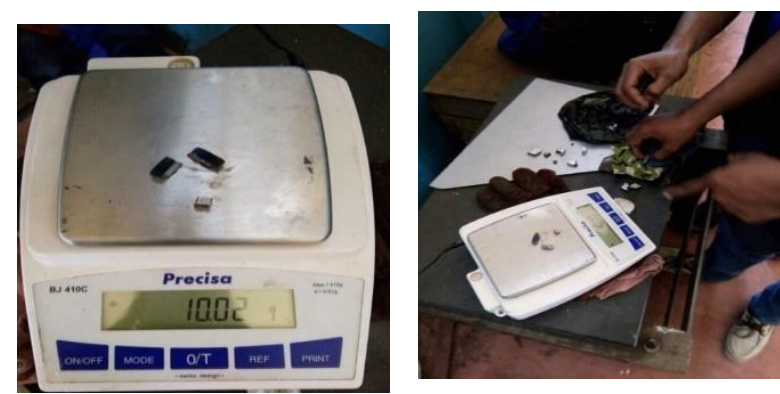

Gambar 3 Proses Penimbangan Material Gear dan Timah Sebagai Perbandingan

\subsection{Proses Peleburan}

Proses peleburan ini bertujuan untuk menyatukan dua jenis material sebagai sampel Uji Bahan dengan perlakuan, yaitu memandukan material Gear Sprocket dengan Timah, matrial dilebur dengan las gas sebagai cara alternatif karna dalam proses peleburan ini sendiri seharusnya menggunaka tungku yang memadai dalam proses-prosesnya, dalam proses ini besi dilebur dengan dibakar sampai meleleh dan benar-benar menyatu antara logam Gear sprocket dan logam timahnya, dan apabila proses peleburanya selesai, maka biarkan beberapa menit untuk proses pendinginan
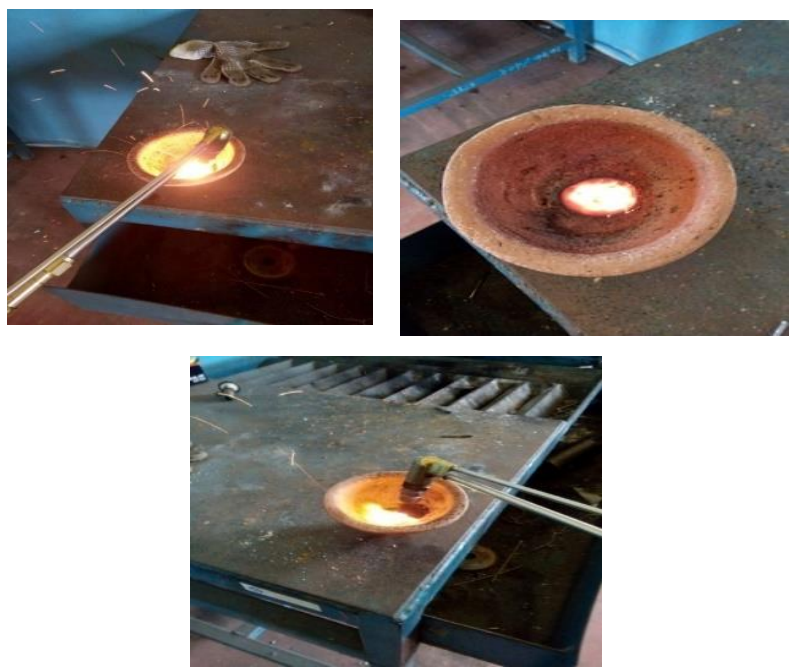

Gambar 4. Proses Peleburan

\subsection{Proses Pengujian}

Setelah didapat hasil sampel material yang sudah dilakukan pemaduan, maka dua jenis Material sampel Gear Sprocket yang dilakukan perlakuan maupun tidak, akan dilakukan penguji kekerasan dengan uji Hardness test dengan metode Rockwell.

Metode Rockwell juga menggunakan dua jenis mata uji, yaitu : a) Bola baja yang memiliki diameter 1/16, 1/8, 1/4, 1/2 in.

b) Kerucut intan yang digunakan untuk bahan-bahan yang keras

Yang digunakan dalam Uji Bahan ini sendiri yaitu menggunakan jenis Mata Bola baja berdiameter 1/16 dengan pembebanan $150 \mathrm{~kg}$.
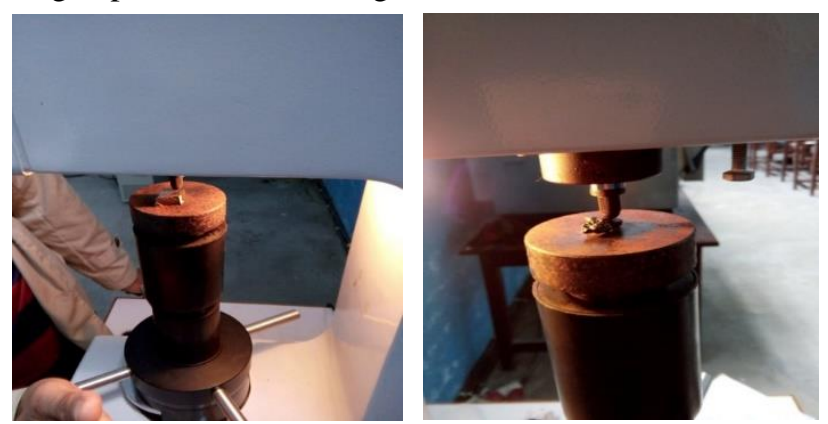

Gambar 5 Pengujian Bahan

\subsection{Hasil}

hasil pengujian dengan metode rockwell terhadap nilai kekerasan Material Gear Sprocket dengan perlakuan Timah maupun tanpa perlakuan Timah didapat hasil pada tabel dibawah ini.

Tabel 1. Data nilai kekerasan Gear Sprocket dengan perlakuan Timah

\begin{tabular}{|l|c|c|c|c|c|}
\hline \multirow{2}{*}{$\begin{array}{c}\text { Dengan } \\
\text { Perlakuan }\end{array}$} & \multicolumn{4}{|c|}{ Nomor Pengujian } & \multirow{2}{*}{ Rata-rata } \\
\cline { 2 - 5 } & $\mathbf{1}$ & $\mathbf{2}$ & $\mathbf{3}$ & $\mathbf{4}$ & \\
\hline Timah & 51,5 & 55 & 50 & 53 & $52,375 \mathrm{HR}$ \\
\hline
\end{tabular}

Berdasarkan Tabel 1 data hasil pengukuran nilai kekerasan tersebut agar mudah dalam pembacaannya, yaitu dengan ditabulasikan dalam bentuk grafik diagram batang (histogram).

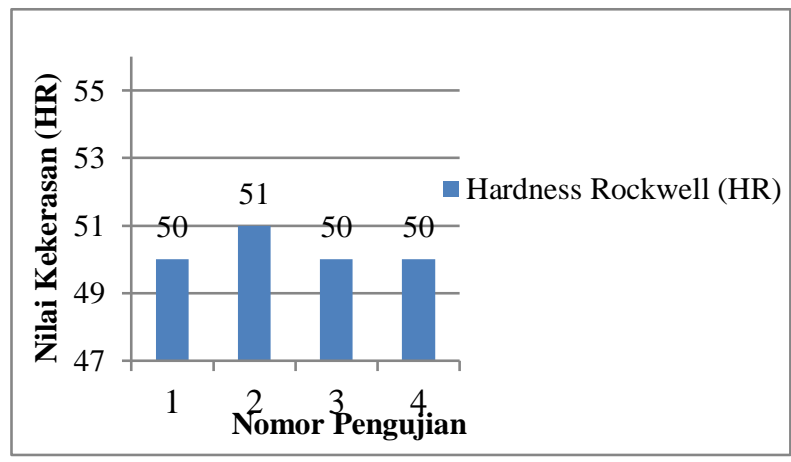

Gambar 6. Histogram Hasil Pengukuran Nilai Kekerasan Gear Sprocket Dengan Perlakuan Timah 
Tabel 2. Data Nilai Kekerasan Gear Sprocket Tanpa Perlakuan

\begin{tabular}{|c|c|c|c|c|c|}
\hline \multirow{2}{*}{$\begin{array}{c}\text { Dengan } \\
\text { Perlakuan }\end{array}$} & \multicolumn{4}{|c|}{ Nomor Pengujian } & \multirow{2}{*}{ Rata-rata } \\
\cline { 2 - 5 } & $\mathbf{1}$ & $\mathbf{2}$ & $\mathbf{3}$ & $\mathbf{4}$ & \\
\hline $\begin{array}{c}\text { Tanpa } \\
\text { Perlakuan }\end{array}$ & 50 & 51 & 50 & 50 & $50,25 \mathrm{HR}$ \\
\hline
\end{tabular}

Berdasarkan Tabel 2 data hasil pengukuran nilai kekerasan tersebut agar mudah dalam pembacaannya, yaitu dengan ditabulasikan dalam bentuk grafik diagram batang (histogram).

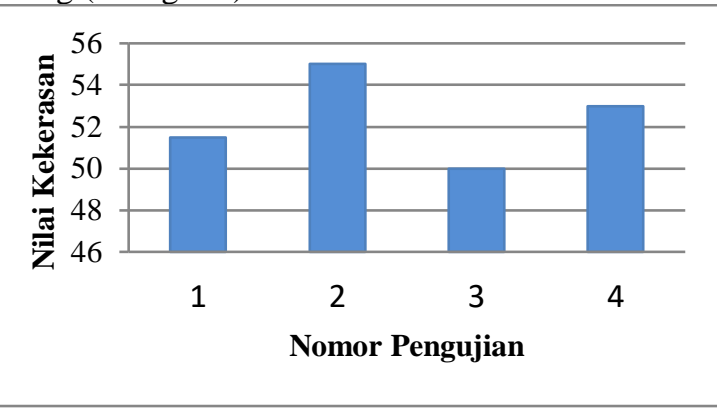

Gambar 7. Histogram Hasil Pengukuran Nilai Kekerasan Gear Sprocket Tanpa Perlakuan
Pada material Gear Sprocket dengan campurn Timah didapat nilai kekerasan rata-rata $52,375 \mathrm{HR}$ atau meningkat $21 \%$ dari nilai kekerasan tidak dilakukan pencampuran, untuk material yang tidak dilakukan pencampuran itu sendiri didapat hasil nilai kekerasan rata-rata 50,25 HR sifat material Gear Sprocket ini lebih rendah $21 \%$ dari material yang dilakukan pencampuran dengan Timah, tetapi material itu sendiri didapat hasil kekerasan yang stabil.

Hal ini dapat dijelaskan jika melihat struktur mikro material tersebut bahwa timah tidak bisa memberikan kualitas hasil kekeraan yang baik, tetapi timah bagus apabila hanya digunakan sebagai pelapis luarnya saja sebagai penahan anti korosi dan karat misalnya. karena timah memiliki kepadatan yang rendah, jadi Timah kurang bagus untuk dijadikan bahan penambah atau paduan jenis-jenis sperpart Gear Sprocket tersebut, karna Gear Sprocket ini sendiri memerlukan material pemadu/penambah yang strukturnya ulet kerasa dan padat, karna beban dari cara kerja Gear Sprocket itu sendiri harus memiliki ketahanan yang benar-benar kuat. Namun dalam penelitian ini tidak dilakukan penelitian lebih lanjut tentang struktur mikro dari material paduan Gear Sprocket dengan Timah tersebut, berdasarkan hasil uji kekerasan material ini yaitu untuk mengetahui Timah memiliki kualitas yang baik atau tidak apabila dilakukan

Setelah melakukan pengujian dan diperoleh data dari perbandinga dengan nila 10:2 Ons sebagai proses pengujian tersebut, langkah selanjutnya pencampuran ini untuk sampel proses pengujian bahan membandingkan data hasil pengujian tersebut terhadap material ini pengaruh media pendingin pada nilai kekerasan paduan gear sprocket dan timah

\section{Kesimpulan}

Tabel 3. Perbandingan data hasil pengukuran nilai kekerasan paduan timah dan tanpa perlakuan

\begin{tabular}{|c|l|c|c|c|c|c|}
\hline No & $\begin{array}{c}\text { Variasi } \\
\text { Perlakuan }\end{array}$ & \multicolumn{4}{|c|}{ Poin } & $\begin{array}{c}\text { Rata- } \\
\text { rata }\end{array}$ \\
\hline 1 & Timah & 51,5 & 55 & 50 & 53 & 55 \\
\hline 2 & Tanpa & 50 & 51 & 50 & 50 & 50 \\
\hline
\end{tabular}

Berdasarkan Tabel 3 data hasil pengukuran nilai $b$ kekerasan tersebut agar mudah dalam pembacaannya, yaitu dengan ditabulasikan dalam bentuk grafik diagram batang (histogram) dibawah ini.

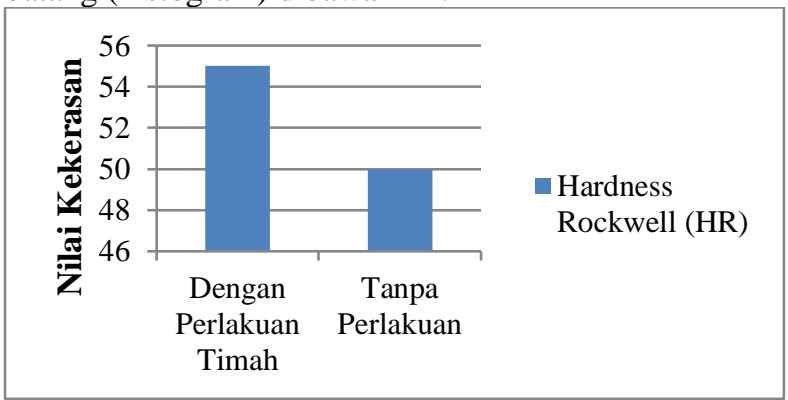

Gambar 8. Histogram Hasil Pengukuran Nilai Kekerasan Gear Sprocket Dengan Perlakuan Dan Tanpa Perlakuan
Dari hasil yang didapatkan pada pembahasan bab sebelumnya, untuk itu ada beberapa hal yang dapat disimpulkan yaitu sebagai berikut :

a) Pemaduan Timah dengan Material Gear Sprocket, di Dapat nilai hasil 52,375 HR, walaupun hasil material yang dilakukan pencampuran itu sendiri meningkat pencampuran dengan perbandingan Material Gear Sprocket 10 dan Timah 2 Ons tersebut, tetapi hasil kekerasan dari Material itu sendiri tidak stabil

Material Gear Sprocket yang tidak dilakukan pencampurandengan Material Timah mendapat hasil nilai pengujian nilai rata-rata 50,25 $\mathrm{HR}$, hasil nilai kekerasannya lebih rendah dari Matarial yang dilakukan pencampuran, tetapi struktur kekerasan dari material dasar Gear Sprocket tersebut stabil.

\section{Daftar Rujukan}

[1] Amanto. Hari dan Daryanto., "Ilmu Bahan", Bumi Aksara, Jakarta, 1999 [2] Surdia.Tata.,

[2] Anhar,Muh ,2020,Pengaruh Variasi Media Pendingin Terhadap Nilai Kekerasan Paduan Gear Sprocket Aisi 1020 Dengan Timah Melalui Heat Treatment,SIMETRI,10(10,pp 279 - 284,

[3] Annonim, Pengetahuan bahan

[4] ASM Handbook Vol.2., "Properties And Selection: Nonferrous Alloys And Spesial Purpose Materials"

[5] Chijiwa,.K., “Teknik Pengecoran”. PT. Pradya Paramita, Jakarta, 1992 sebesar $21 \%$ dari material yang tidak dilakukan DOI: https://doi.org/10.31959/js.v10i1.377

Journal of Applied Mechanical Engineering and Renewable Energy (JAMERE) 
[6] Sudjana Hardi, "Teknik Pengecoran Jilid I", Direktorat [7] Pratiwi,DK, Chandra, H., "PanduanPratikumMaterial Teknik". Pembinaan Sekolah Menegah Kejuruan DepDikNas, Jakarta, Laboratorium Mettalurgi Universitas Sriwijaya 2008 [5] ASM Handbook Vol.3, "Alloy Phase Diagram" 
